\title{
AMEAÇAS TECNOLÓGICAS NA ZONA DE INTERESSE PORTUÁRIA DE PARANAGUÁ-PR
}

\author{
Patrícia Milla Gouvêa \\ Instituto Federal do Paraná - Campus Paranaguá \\ Paranaguá, Paraná - Brasil \\ patricia.milla@yahoo.com.br \\ Emerson Luis Pawoski da Silva \\ Instituto Federal do Paraná - Campus Paranaguá \\ Paranaguá, Paraná - Brasil \\ emprovoski@gmail.com

\section{Emerson Luis Tonetti} \\ Instituto Federal do Paraná - Campus Paranaguá \\ Paranaguá, Paraná - Brasil \\ emerson.tonetti@ifpr.edu.br
}

Recebido em 07/09/2020. Aprovado em 26/10/2020.

DOI: $\underline{\text { dx.doi.org/10.5380/guaju.v6i2.76344 }}$

\section{Resumo}

O desenvolvimento, o uso, as incompatibilidades e o constante debate sobre tecnologia são temas presentes em sociedades de risco. O risco se apresenta em situações ou áreas em que existe a probabilidade de ocorrer algum tipo de perigo ou desastre com uma população considerada vulnerável. Os acidentes são considerados a ampliação e manifestação dos riscos. Dessa forma, acidentes tecnológicos são originados na amplitude dos riscos tecnológicos. A cidade de Paranaguá, no litoral do estado do Paraná, tem como principal atividade econômica a portuária. O Porto Dom Pedro II movimenta muitos materiais como mercadorias, alimentos, fertilizantes e grãos, provendo renda e emprego na região. A Zona de Interesse Portuária (ZIP) se localiza adjacente às áreas residenciais, de forma que eventos que ocorrem em um local podem atingir outros. A movimentação e armazenamento de substâncias químicas no porto ou na ZIP gera risco de explosão e incêndio que ameaça a população do entorno. Este estudo teve como objetivo 
estudar a possibilidade de incêndio e explosão gerada por vapor (BLEVE - Boiling Liquid Expanding Vapor Explosion) de duas empresas da ZIP e suas consequências na sociedade residente nas proximidades. Através de dados de Relatórios Line up portuários e da simulação de acidentes pelo software ALOHA foram obtidos os efeitos em áreas a partir de possível explosão. Foram determinadas as zonas: potencialmente letal em até 951 metros; com queimaduras de segundo grau em até $1,4 \mathrm{~km}$; e com efeitos de dor em até $2,1 \mathrm{~km}$. Todas as três zonas atingem áreas residenciais, colocando essa sociedade em risco.

Palavras-chave: Tecnologia. Incêndio. Sociedade. BLEVE.

\title{
Technological Threats Risk in the Zone of Port Interest of Paranaguá-PR
}

\begin{abstract}
The development, use, incompatibilities and constant debate about technology are common topics in risk societies. The risk presents itself in situations or areas where there is a probability of some type of danger or disaster occurring with a population considered vulnerable. Accidents are considered the expansion and manifestation of risks. Thus, technological accidents are caused by the extent of technological risks. The main economic activity of the city of Paranaguá on the coast of the state of Paraná is its port. The Porto Dom Pedro II transports several materials as goods, food, fertilizers and grains. The port provides income and employment in the region. The Zone of Port Interest (ZPI) is located adjacent to residential areas in the city and events that occur in one location can reach others. The movement and storage of chemical substances in the port or in the ZIP creates a risk of explosion generated by steam (BLEVE- Boiling Liquid Expanding Vapor Explosion) and fire that threatens the surrounding population. This paper aimed to study the possibility of fire and explosion of two ZPI companies, as their consequences to the nearby society. Effects on areas from possible explosion were obtained through data from Line up reports of the port and accident simulation with ALOHA software. The determined zones were: potentially lethal up to 951 meters; with second degree burns up to $1.4 \mathrm{~km}$; and with pain effects up to $2.1 \mathrm{~km}$. All three zones reach residential areas. This context sets this society in risk.
\end{abstract}

Keywords: Technology. Fire. Society. BLEVE. 


\section{Introdução}

A definição de risco baseia-se na possibilidade de uma ocorrência ou episódio futuro arriscado ou incerto sobre um local, grupo de pessoas e outros seres vivos considerados, por diversas razões, em estado de vulnerabilidade. É probabilidade de perigo, trazendo a possibilidade de ameaça física para a sociedade e/ou para o ambiente. O ser humano, organizado em sociedades cada vez mais complexas e desenvolvidas, está sujeito a riscos e a fenômenos naturais intensos que comprometem o equilíbrio entre o meio ambiente e a sociedade. Beck (2015) define que risco significa a antecipação da catástrofe. Os riscos dizem respeito à possibilidade de acontecimentos e desenvolvimentos futuros tornam a apresentar um estado do mundo que não existe. Enquanto as catástrofes estão todas determinadas espacial, temporal e socialmente, a antecipação da catástrofe não conhece qualquer concretização espacial, temporal ou social.

Segundo a ANPC (2016), durante muitos séculos as catástrofes estiveram associadas apenas aos fenômenos de origem natural (como terremotos, tempestades, erupções vulcânicas, tornados, furacões etc.), porém, o avanço do desenvolvimento tecnológico, a criação de novas indústrias, o uso de mais e maiores quantidades de substâncias perigosas originaram um novo tipo de evento catastrófico: os acidentes tecnológicos, que são acontecimentos súbitos e não planejados, causadores de danos graves aos seres humanos e ao ambiente.

Existem diversos sinônimos para o termo "acidente tecnológico" (acidente industrial, acidente ampliado, evento agudo, desastre tecnológico), que variam de acordo com o país, a causa e a consequência do evento (LUIZ, 2013). A Organização Mundial de Saúde - OMS (1999) define que acidentes tecnológicos são originados na amplitude dos riscos tecnológicos. Segundo essa obra, esses riscos provenientes de um contexto urbano-industrial levam em consideração o transporte de materiais e pessoas (via aérea, rodoviária, ferroviária ou marítima), uso de máquinas pesadas e de rápida movimentação, uso de sistemas de altas temperaturas, pressões e grande voltagem elétrica na manufatura, armazenamento, utilização e disposição de materiais perigosos.

Segundo Dagnino e Capri Junior (2007), o risco se apresenta em situações ou áreas em que existe a probabilidade, suscetibilidade, vulnerabilidade, acaso ou azar de ocorrer algum tipo de ameaça, perigo, problema, impacto ou desastre. São quatro os tipos de risco mais frequentes na literatura, sendo eles: natural, tecnológico, social e ambiental. Riscos naturais 
são aqueles que não podem ser facilmente atribuídos ou relacionáveis à ação humana; já risco social representa a maior parte dos riscos, devido às causas sociais e consequências humanas. O risco tecnológico, segundo Sevá Filho (1988 apud DAGNINO; CAPRI JUNIOR, 2007), existe quando pelo menos um dos três fatores (processo de produção, processo de trabalho e condição humana) for encontrado, ou a probabilidade de um problema causado por ele. O risco ambiental envolve o ambiente natural, tornando-se um termo sintético que abriga os demais (natural, tecnológico e social).

Beck (2015) menciona que o risco ameaça a vida, sendo que as decisões práticas que acompanham a industrialização científico-técnica e a sua globalização não só ameaçam os fundamentos orgânicos de todas as formas de vida como também a maioria dos seres humanos.

No seu sentido original, o conceito de risco era neutro, pois estava associado a eventos naturais que não fossem de responsabilidade humana, sendo percebido como evento natural e referia-se a uma probabilidade aumentada de um evento ocorrer. Porém, recentemente, o risco é frequentemente tomado como uma premonição. O risco significa perigo e exposição a ele. A magnitude e a natureza global dos riscos atuais são tais que os riscos se tornaram cada vez mais difíceis de quantificar, de prevenir e de anular e, nesse sentido, muitos defendem que se vive na sociedade do risco (MENDES, 2002).

O conceito de sociedade de risco está ligado ao processo de questionamento, à ideia de controlar e compensar as incertezas e perigos industriais gerados. A dinâmica da sociedade de risco se baseia menos na suposição de que a sociedade tem de viver em um mundo de perigos inéditos e mais na ideia de que ela vive em um mundo que tem de decidir o seu futuro nas condições de insegurança produzida por si próprio. Essa concepção significa que a sociedade deixou de controlar os perigos gerados pela própria modernidade e exemplifica que as alterações climáticas são fruto da industrialização, que desrespeita sistematicamente as suas consequências para a natureza e para o ser humano (BECK, 2015).

Segundo Giddens (2017), ao calcular possíveis ganhos e perdas, ou seja, o risco, o capitalismo moderno colocou-se no futuro. E é nesse sentido que na sociedade atual há muitos riscos originados devido a grandes acidentes tecnológicos ocorridos no passado, como o caso do acidente nuclear de Chernobyl ocorrido em 1986; a explosão da plataforma de petróleo Piper Alpha em 1988; o vazamento de óleo do navio Exxon Valdez em 1989, entre muitos outros. Tais acidentes serviram de fonte e pesquisas científicas para cálculo de ganhos e perdas e originaram o que se chama hoje de seguros privados ou comerciais. 
Deu-se início a um sistema de gestão de riscos destinado a proteger pessoas, bens materiais e meio ambiente contra riscos tecnológicos como explosões, incêndios, derramamentos, em que indústrias e pessoas são confortadas pela ideia de segurança que expulsa o destino através de um contrato ativo com o futuro. A razão do seguro existir se dá pela crença de que o futuro é construído pelo homem e a atividade seguradora, embora sirva para proporcionar mais segurança, alimenta-se do risco e das atitudes humanas em relação a ele. Quando uma indústria contrata um seguro para se proteger de uma explosão ou incêndio, o risco não desaparece; apenas é transferido para a seguradora. Por essas razões, Mendes (2002) relata que a ideia de risco sempre andou associada à modernidade, mas na época atual ela assume uma importância nova e peculiar. O risco era considerado um meio de regular o futuro, de normalizá-lo e de colocá-lo sob domínio. Mas as coisas não se passaram assim. As tentativas que a sociedade faz para controlar o futuro acabam por se voltar contra ela mesma, forçando-a a procurar novas formas de viver com a possibilidade e os efeitos de acidentes.

Um acidente tecnológico ocorreu em abril de 2015 no complexo portuário de Santos (São Paulo), onde 6 tanques contendo gasolina ou etanol queimaram durante 8 dias (Figura 1). O incêndio iniciou em apenas um tanque e com a alta temperatura atingiu os demais, transformando-se em um característico acidente em cadeia (SIMA, 2015; OLIVEIRA; LACERDA; OLIVEIRA, 2017). 
Figura 1 - Registro fotográfico de incêncio ocorrido em Santos no ano de 2015

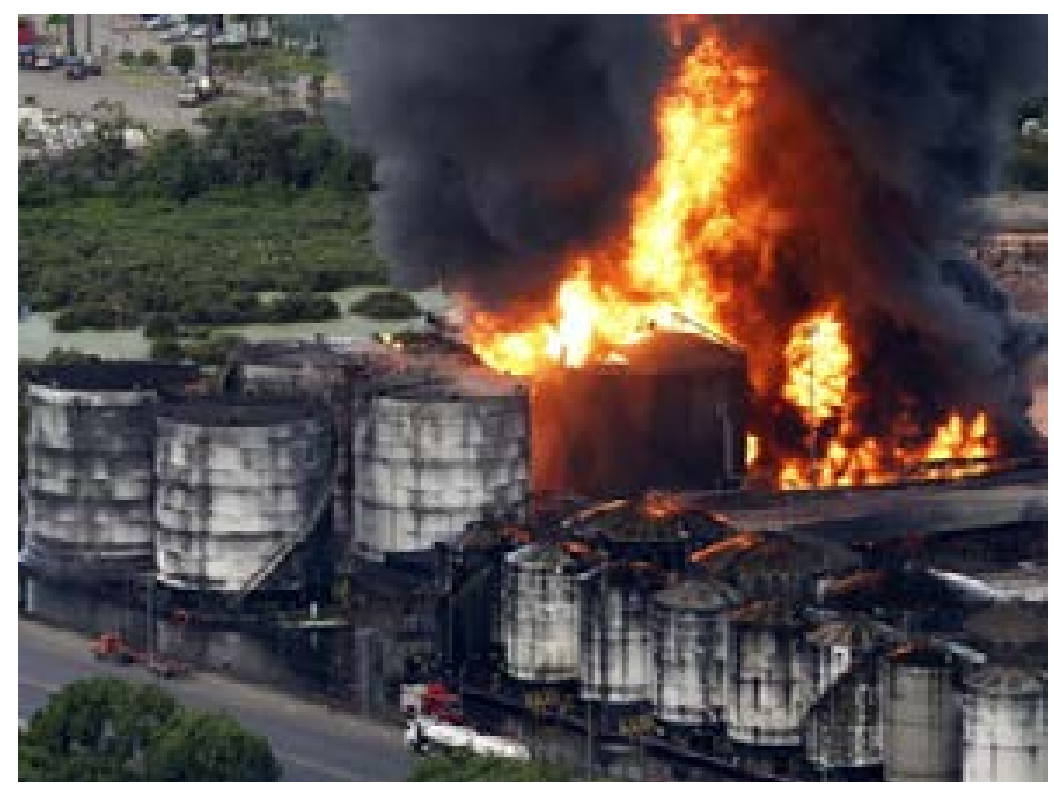

Fonte: LYRA; LUCIO; RODRIGUES (2015).

Um incêndio pode ser acompanhado pela ocorrência de um BLEVE. A palavra BLEVE é um acrônimo para Boiling Liquid Expanding Vapor Explosion, em tradução para o português: “Expansão explosiva da nuvem de vapor de um líquido em ebulição”. Esse termo foi primeiramente introduzido em 1957, por J. B. Smith, W. S. Marsh e W. L. Walls da Factory Mutual Research Corporation. Ele pode ser definido como a perda de contenção de um líquido ou de um gás liquefeito que está superaquecido nas condições atmosféricas (CCPS, 2010). Esse fenômeno resulta em uma rápida e vigorosa evaporação da parte líquida contida no vaso e na produção de ondas de pressão. Tal reação ocorre geralmente em tanques de estocagem, não sendo observado em tanques de processo (os quais têm suas entradas e saídas com transição do produto químico dentro do processo), já que não há acúmulo da substância nos últimos para sofrer todas as etapas necessárias à ocorrência do BLEVE (CCPS, 2019).

O fenômeno não gera necessariamente efeitos térmicos, podendo ocorrer em vasos que contenham líquidos inflamáveis, sendo a explosão seguida de rápida combustão de combustível e dando origem a uma bola de fogo imediatamente após a explosão, cujo potencial de dano é de $100 \%$ de fatalidade para as pessoas que estejam dentro do raio dessa bola (CCPS, 2010). A reação BLEVE pode ocorrer por várias razões, como pressão excessiva no recipiente, impacto mecânico ou corrosão ou exposição do recipiente pressurizado a um fogo externo (CCPS, 2019). 
Freitas e Tonetti (2016) e Tonetti, Nucci e Valaski (2016) destacaram o potencial poluidor, a incompatibilidade de usos na Zona de Interesse Portuário (ZIP) no município de Paranaguá do estado do Paraná e a proximidade desses usos com a Zona de Requalificação Urbana da cidade. Tonetti, Schröder e Nucci (2015) evidenciaram conjuntos de residências tendo no entorno empresas com potencial risco de explosão. Torrisi, Paula e Wroblewsky (2017) demonstraram a fragilidade das ferramentas de gestão da Administração dos Portos de Paranaguá e Antonina (APPA) e do município no monitoramento e prevenção dos potenciais riscos de explosão e incêndio na ZIP, com riscos para as demais zonas urbanas do município. Já Gouvêa e Tonetti (2017) classificaram e mapearam a distribuição das substâncias químicas na mesma ZIP.

O avanço industrial do município ocorreu de forma desordenada, possibilitando novos acidentes relacionados a atividades e produtos movimentados na área portuária. Conforme a concepção de Mendes (2002), a sociedade da zona portuária de Paranaguá pode apresentar vulnerabilidade de riscos tecnológicos.

Este estudo tem por objetivo verificar a possibilidade de um acidente devido à proximidade de movimentação de granéis (quimicamente incompatíveis), se a população local seria afetada ou não caso o acidente viesse a acontecer e, ainda, seu enquadramento como sociedade de risco. Neste estudo priorizou-se o risco tecnológico, por abranger uma área de atividades industriais da atualidade ligadas entre si, existindo a probabilidade de perigo e trazendo a possibilidade de ameaça física para a sociedade e/ou para o ambiente.

\section{Metodologia}

\section{Área de estudo}

O Porto Dom Pedro II, da cidade de Paranaguá no estado do Paraná, é considerado o maior porto graneleiro da América Latina, sendo um dos mais importantes centros de comércio marítimo do mundo (GOUVÊA; TONETTI, 2017). Sua localização estratégica e a facilidade de seus acessos rodoviários (BR 277, BR 376 e BR 116), ferroviários (Malha Sul) e marítimos (Canal da Galheta) (PORTOSDO PARANÁ, 2018) contribui para a expansão portuária e econômica do município, que tem uma população estimada de aproximadamente 153 mil habitantes (IPARDES, 2020). As instalações do porto e as ele relacionadas estão inseridas na 
Zona de Interesse Portuária (ZIP) e têm proximidade com as demais zonas da cidade (Figura 2), cuja principal característica é a predominância do uso residencial, destacando-se a Zona de Requalificação Urbana (ZRU) (PARANAGUÁ, 2007).

Figura 2 - Proximidade dos usos portuários e correlatos com usos não portuários e residenciais em segmento urbano do município de Paranaguá

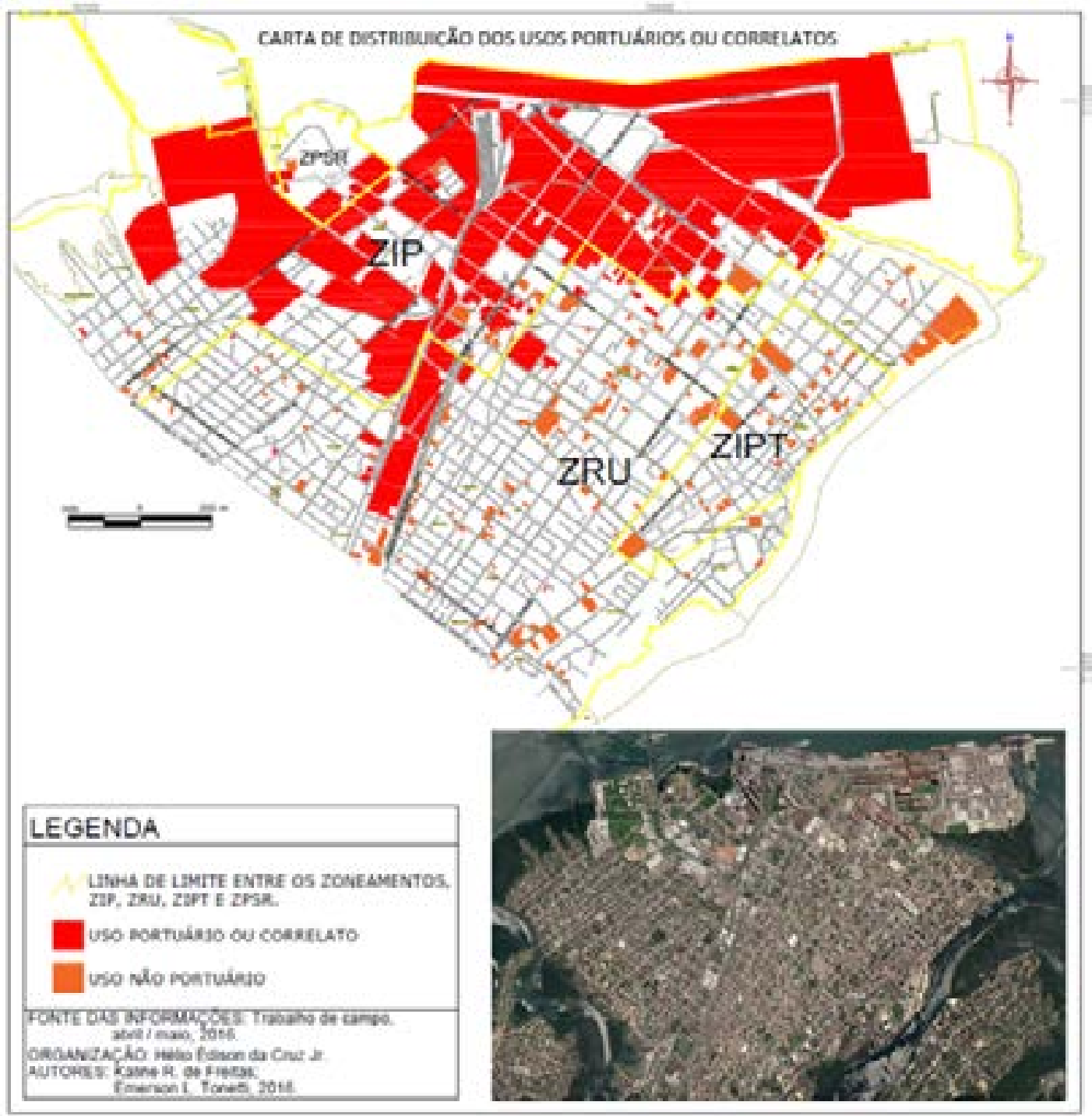

Fonte: Adaptado DE FREITA; TONETTI (2016); GOOGLE EARTH PRO (2018).

Legenda: ZIP - Zona de Interesse Portuário; ZRU - Zona de Requalificação Urbana; ZIPT - Zona de Interesse Patrimonial e Turístico; ZPSR - Zona de Proteção ao Santuário do Rocio.

Acidentes que ocorrem na ZIP podem atingir áreas residências devido a essa proximidade. Entre os possíveis acidentes se destacam explosões e incêndios (GOUVÊA; 
TONETTI, 2017). Na ZIP, como medida de segurança, terminais que movimentam granéis inflamáveis, principalmente os líquidos de baixo ponto de fulgor (ou ponto de inflamação, a menor temperatura na qual um combustível liberta vapor em quantidade suficiente para formar uma mistura inflamável por uma fonte externa de calor), possuem acoplado em seus tanques de armazenamento válvulas do tipo alívio e pressão ou válvulas de segurança, as quais liberam vapores inflamáveis quando ocorre um aumento da temperatura interna da substância devido a um aumento da temperatura atmosférica.

Duas empresas localizadas na ZIP (Figura 3) foram selecionadas em função da proximidade, das propriedades químicas dos produtos armazenados e das características dos compartimentos de armazenagem.

Figura 3 - Indicação e delimitação das empresas pesquisadas

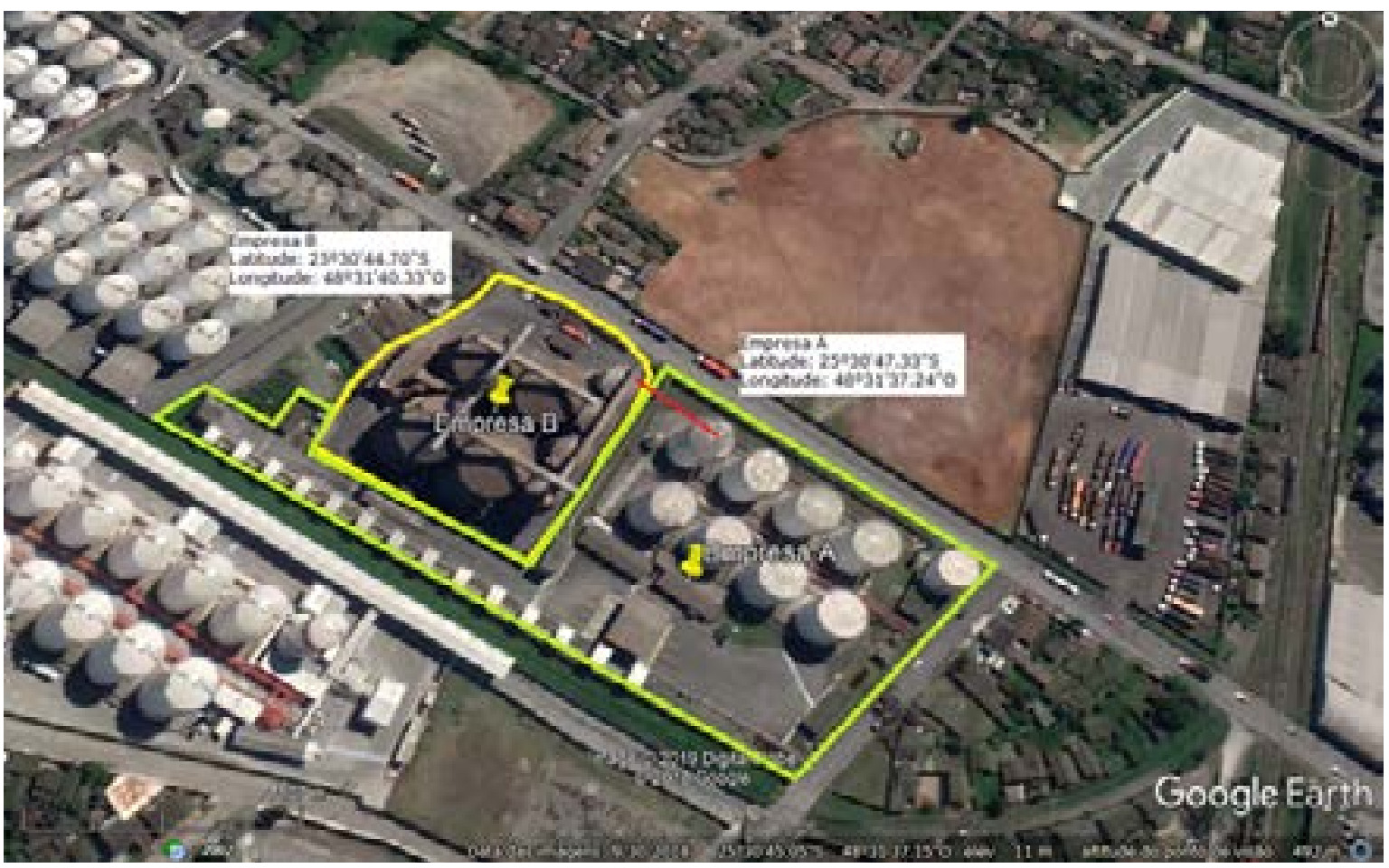

Fonte: GOOGLE EARTH PRO (2018).

Legenda: Linha vermelha: distância de 46 metros entre os pontos mais próximos suscetíveis a explosões. 


\section{Procedimentos}

Este estudo apresentou uma pesquisa bibliográfica e uma prática para definir sociedade de risco e verificar essa condição na ZIP e ZRU.

A pesquisa bibliográfica utilizou como fontes indexadores como Capes Periódicos e Web of Science, bem como livros e documentos, para pesquisar as palavras-chave: risco, sociedade de risco, acidentes e acidentes tecnológicos. Os resultados foram organizados para conceituar sociedade de risco e acidentes tecnológicos, assim como para apresentar um histórico da evolução e relação entre esses conceitos, discutidos acima.

O estudo prático foi dividido em três etapas: (1) foram determinadas as distâncias entre as movimentações dos produtos e a possibilidade de explosão seguida de incêndio através de consulta em Relatórios Line up (APPA, 2020), verificação no Google Earth Pro versão 7.3.2.5776 e visita in loco; (2) esses dados foram aplicados em um simulador ALOHA versão 5.4.7 utilizado para emergências químicas para estimar a distância atingida em caso de uma explosão (ILIĆ-KOMATINA; GALJAK; BELOŠEVIĆ, 2018). Para a simulação, foi suposta uma explosão seguida de incêndio (por bola de fogo), caracterizando um BLEVE; (3) aplicação da zona de ameaça obtida no simulador para os mapas físicos e em satélite através do software Google Earth Pro versão 7.3.2.5776 para obter os locais que possivelmente seriam atingidos na cidade de Paranaguá com o levantamento dos impactos ambientais e sociais, bem como a concepção da sociedade de risco tecnológico local.

\section{Resultados e Discussão}

Verificou-se que a empresa A (os nomes das empresas foram ocultados para manter a confidencialidade) realiza as atividades de movimentação de granéis líquidos inflamáveis (como diesel, etanol e gasolina) através do recebimento do produto por via marítima, armazenamento em tanques de aço carbono com válvulas do tipo alívio e pressão e descarga do produto através de caminhões tanque e vagões tanque. A empresa possui um tanque de armazenamento de água para incêndio e sistema de prevenção a incêndios. $A$ empresa B realiza atividades de movimentação de granéis sólidos (como farelo de soja, soja, milho e cevada) através do recebimento, armazenamento e descarga do produto por meio de caminhões de carga sólida. Esses dados foram utilizados na simulação (Quadro 1). 
Quadro 1 - Dados levantados e imputados para simulação

\begin{tabular}{|c|c|c|}
\hline Parâmetros & Tipo & Dados \\
\hline Data & Simulação & $11 / 06 / 2019,16: 00 \mathrm{hrs}$ \\
\hline \multirow[t]{4}{*}{ Local } & Localização & Paranaguá - Paraná \\
\hline & Altitude & 5 metros \\
\hline & Latitude & $25^{\circ} 31^{\prime}$ \\
\hline & Longitude & $48^{\circ} 30^{\prime}$ \\
\hline \multirow[t]{2}{*}{ Vento } & Velocidade & 8 nós \\
\hline & Sentido & Oeste para Leste \\
\hline \multirow[t]{3}{*}{ Tempo } & Previsão & Parcialmente nublado \\
\hline & Temperatura & $25^{\circ} \mathrm{C}$ \\
\hline & Umidade & $72 \%$ \\
\hline \multirow[t]{4}{*}{ Substância química } & Etanol & \\
\hline & Tipo & Cilíndrico vertical \\
\hline & Diâmetro & 20 metros \\
\hline & Altura & 19 metros \\
\hline \multirow[t]{2}{*}{ Tanque } & Volume (máximo) & 5969 metros cúbicos \\
\hline & Volume do tanque no momento do acidente & $25 \%$ cheio \\
\hline
\end{tabular}

Fonte: Os autores (2019).

A simulação indica que após a formação do BLEVE, em um período de 60 segundos de exposição, um raio de até $2,1 \mathrm{~km}$ ao redor do ponto do acidente poderá ser atingido por uma bola de fogo de 612 metros de diâmetro com período de queima de 30 segundos, sendo os danos mais sérios quanto mais perto estiver do local do acidente. A área atingida é dividida em 3 círculos, identificados por cores quentes, em que cada cor representa a gravidade do dano que pode ser causado à comunidade local. A área vermelha, representada por um raio de até 951 metros do acidente, pode causar um acidente fatal; a área laranja, representada por um raio de até 1,4 km do ponto do acidente, pode causar queimaduras de segundo grau; e a área amarela, representada por um raio de até 2,1km, pode causar dor ou sequelas à comunidade local (Figura 4). 
Figura 4 - Efeitos em seres vivos em 60 segundos de exposição
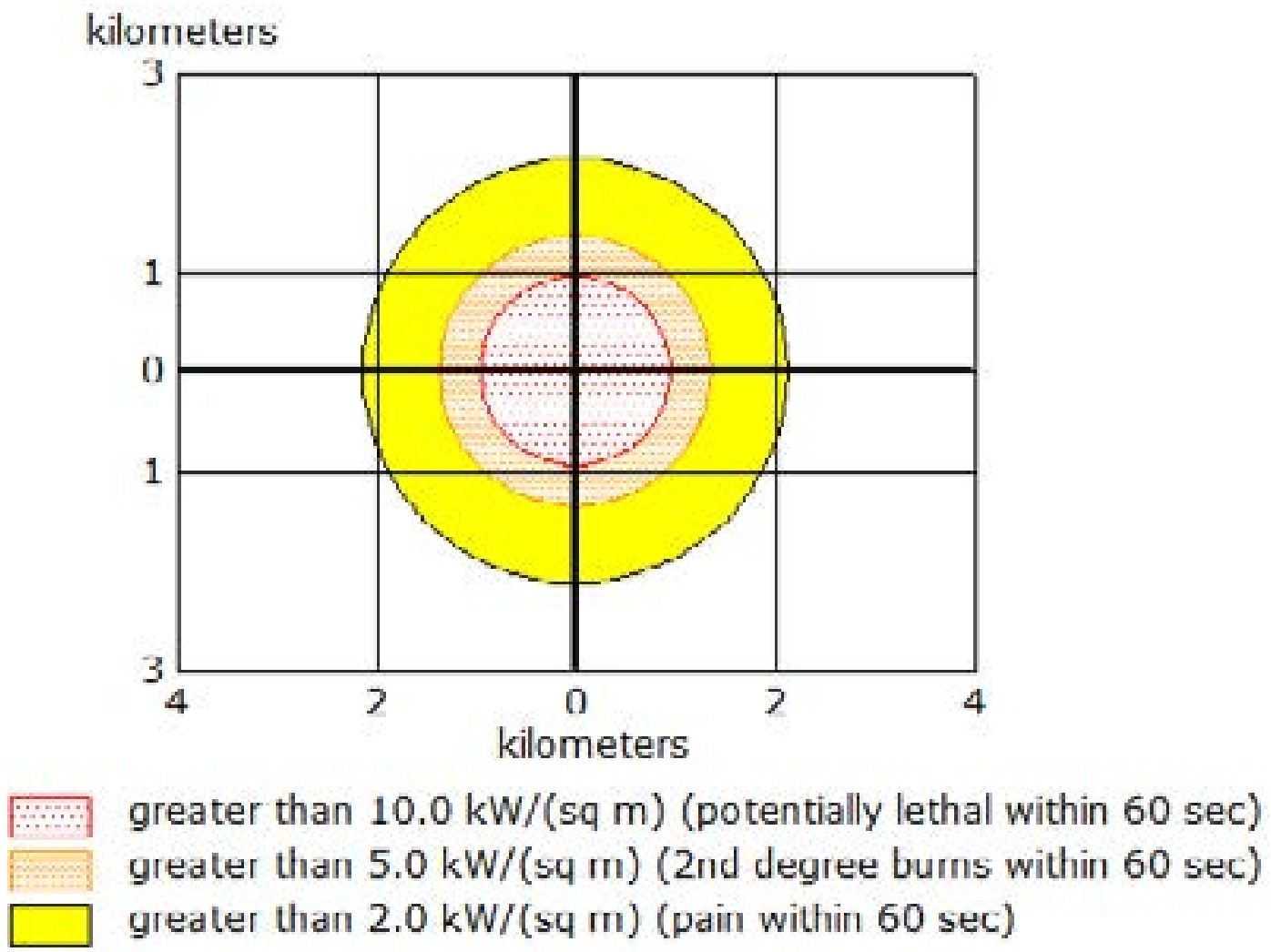

Fonte: Os autores (2019).

Legenda: área vermelha: potencialmente letal em até 951 metros; área laranja: queimaduras de segundo grau em até $1,4 \mathrm{~km}$; área amarela: dor em até $2,1 \mathrm{~km}$.

Foram mapeadas as áreas de ameaça a partir do ponto onde foi simulado o acidente (Figura 5). Foram identificados 27 bairros que poderiam ser atingidos, que são: Jardim Araçá, Porto dos Padres, Vila Cruzeiro, Padre Jackson, Serraria do Rocha, Bockmann, Raia, Palmital, Vila Paranaguá, Eldorado, Correia Velho, Tuiuti, Campo Grande, Estradinha, Ponta do Caju, Alto São Sebastião, Costeira, 29 de Julho, Vila Guadalupe, Zona Industrial, Villa Alboitt, Vila Rute, Vila Portuária, Vila Guarani, Beira Rio, Rocio e Vila Cruzeiro. Além dos bairros citados, boa parte da rota principal de caminhões que circulam na área portuária poderia ser atingida, assim como quase todos os terminais e empresas localizadas na Zona de Interesse Portuária e navios atracados nos berços. Além das áreas residenciais, outros ambientes como estuário, vegetação e canais hídricos seriam atingidos e, assim, o efeito poderia ser potencializado e ter maior duração em toda região. 
Figura 5 - Área de ameaça plotada em imagem por satélite na cidade de Paranaguá

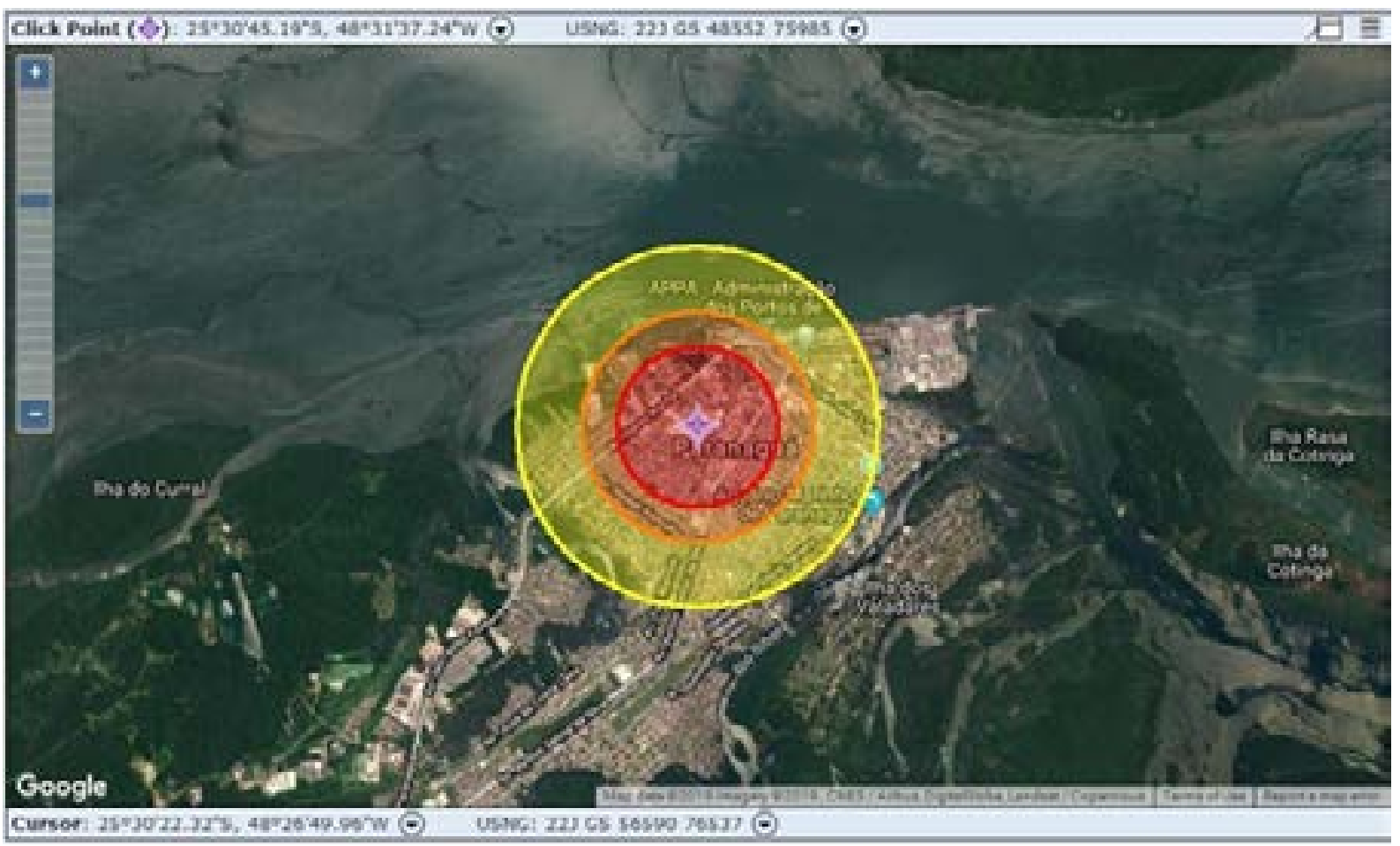

Fonte: Os autores (2019); GOOGLE EARTH PRO (2019).

Legenda: área vermelha: potencialmente letal em até 951 metros; área laranja: queimaduras de segundo grau em até $1,4 \mathrm{~km}$; área amarela: dor em até $2,1 \mathrm{~km}$.

Analisando a área de abrangência atingida pela área de ameaça calculada pelo software, verifica-se que a empresa B encontra-se dentro da área de ameaça onde o risco é potencialmente letal, ou seja, qualquer ponto dentro da empresa poderia ser atingido pelo BLEVE em caso de ocorrência do acidente. Nesse caso, supondo que a explosão atingisse o ponto mais próximo entre os locais, mapeado em 46 metros, supõe-se que haveria uma segunda explosão em função da carga movimentada ser altamente combustível, devido à poeira gerada no seu armazenamento, gerando uma condição favorável à explosão (fonte de ignição). Supõe-se ainda que, a partir dessa segunda explosão, poderia ocorrer uma terceira ou mais explosões, conforme estas fossem atingindo mais materiais combustíveis em outros terminais e empresas dentro da área de abrangência.

Nesse contexto, verifica-se que ocorreria a potencialização do risco de incêndio e explosão de ocorrer vários acidentes a partir de um acidente iniciado na empresa A. Dentro da área de abrangência encontrada, à medida que os terminais fossem sendo atingidos, 
ocorreriam novas explosões, incêndios ou BLEVEs, os quais poderiam gerar novas bolas de fogo e atingir outros locais e terminais, gerando um conjunto de acidentes, podendo chegar até a uma tragédia descontrolada.

Foram levantados os impactos ambientais e sociais gerados nesse suposto acidente e aplicados na simulação feita no software entre as empresas A e B, tem-se como possíveis impactos, ou seja, a comunidade dos bairros citados ainda estariam expostas:

- a problemas respiratórios devido à alta concentração de gases poluentes lançados na atmosfera;

- $\quad$ à contaminação de rios e mares e morte de peixes;

- $\quad$ à geração de chuva ácida, queima de folhas das árvores e corrosão de espécies nativas;

- a ocasionar interrupção das atividades de outros terminais da região e navios;

- a ocasionar interrupção das atividades de tráfego de caminhões e vagões ao porto de Paranaguá;

- $\quad$ a impactos nas atividades econômicas, como pesca e artesanato local;

- a impactos nas atividades de turismo.

Um cenário de acidente que poderia ser causado gerando as mesmas consequências da simulação descrita seria a ocorrência de um acidente causado devido à incompatibilidade química entre as substâncias movimentadas entre os terminais A e B (TONETTI; NUCCl; VALASKI, 2016; CCPS, 2019). Dessa forma, o contato desses vapores inflamáveis com a poeira gerada no armazenamento dos granéis sólidos da empresa B poderia gerar uma condição favorável à explosão (fonte de ignição) devido à incompatibilidade dessas substâncias, gerando as consequências já elencadas na simulação anterior (TONETTI; SCHRÖDER; NUCCI, 2015; GOUVÊA; TONETTI, 2017).

A simulação apresentada e os dados obtidos apresentam mais uma vez números preocupantes, indicando a necessidade de uma gestão de riscos na região (TORRISI; PAULA; WROBLEWSKY, 2017) com a finalidade de prevenir a exposição ao risco não só frente à população local e ao meio ambiente, mas também frente aos demais usos industriais/ portuários. 


\section{Conclusão}

A tecnologia tem influenciado na mudança do conceito ou percepção de risco. O desenvolvimento da tecnologia, por sua vez, tem aumentado o risco tecnológico nos ambientes urbanos, o que faz com que a probabilidade de ocorrer acidentes tecnológicos também aumente.

Contrário a esse ponto, também é interessante notar que a ocorrência de acidentes tecnológicos tem influenciado positivamente no cálculo de ganhos e perdas e, consequentemente, no desenvolvimento de novas tecnologias para atuarem de forma preventiva ou compensatória. Existem algumas tecnologias usadas para prever a catástrofe e devido a isso, as sociedades organizam planos de evacuação, prevenção e mitigação cada vez mais eficientes, já que é impossível impedir o acontecimento da catástrofe.

Esse estudo buscou demonstrar as possíveis ameaças e em destaque explosões consecutivas, sem verificar as medidas de prevenção da APPA e empresas associadas. Para uma avaliação mais detalhada e decisão de ação, é recomendado investigar o planejamento de cada empresa.

A investigação da potencialização dos riscos a acidentes na área portuária de Paranaguá, levando em consideração as substâncias movimentadas, incompatibilidade entre elas e suas características relacionas ao risco de acidentes são fundamentais para compreender a situação global e propor ações que ajudem o município a proteger seus cidadãos, o meio ambiente e seus bens materiais. Foi identificado o risco de acidente entre duas empresas ( $A$ e $B$ ) através de uma simulação de BLEVE e verificadas as áreas de ameaça para a ocorrência do acidente, cuja comunidade estaria exposta em até 2,1 km de raio do ponto central do acidente, em um período de 60 segundos, com danos entre dor, queimaduras de segundo grau e até morte.

Através do mapa estimou-se que cerca de 27 bairros poderiam ser atingidos, inclusive as empresas próximas de armazenamento de sólidos e líquidos inflamáveis, boa parte da rota principal de caminhões de circulação na rota portuária e os berços do porto de Paranaguá, podendo-se gerar uma segunda explosão e assim sucessivamente à medida que o fogo fosse atingindo mais materiais combustíveis. Verifica-se que a empresa B encontrase dentro da área de ameaça onde qualquer ponto dentro da empresa poderia ser atingido pelo BLEVE em caso de ocorrência do acidente. Sugere-se uma segunda causa para a 
mesma simulação, que é o acidente gerado pela incompatibilidade química entre o vapor inflamável gerado pelas válvulas de segurança dos tanques de armazenamento da empresa A e a movimentação de granéis sólidos da empresa $B$.

Agregado aos riscos tecnológicos estão os acidentes tecnológicos, que ocorrem à medida que os riscos surgem. A percepção do risco mudou ao longo dos anos conforme os eventos ocorridos, aliada à mudança do conceito de risco. De uma forma geral, a sociedade de hoje tem sido a sociedade do risco, motivada pelos riscos criados por ela mesma através do desenvolvimento urbano-industrial e novas tecnologias, sendo esse o contexto da ZIP e ZRU de Paranaguá.

\section{Referências}

ADMINISTRAÇÃO DOS PORTOS DE PARANAGUÁ E ANTONINA (APPA). Line up Corredor de exportação. Disponível em: http://www.appaweb.appa.pr.gov.br/appaweb/pesquisa. aspx?WCl=relEmitirLineUpCorex\&Criterio=PageSize=20\&sqIFLG_STATUS=0. Acesso em: 25 mar. 2020.

AUTORIDADE NACIONAL DE PROTEÇÃO CIVIL (ANPC). Riscos Naturais e Tecnológicos. Portugal, 2016. Disponível em: http://www.proteccaocivil.pt/RiscosVulnerabilidades/Pages/Apresentacao.aspx. Acesso em: 24 mar. 2020.

BECK, U. Sociedade de risco mundial. Lisboa: Edições Almedina, 2015.

CENTER FOR CHEMICAL PROCESS SAFETY (CCPS). Guidelines for Vapor Cloud, Explosion, Pressure Vessel Burst, BLEVE and Flash Fire Hazards. 2. Ed. New Jersey: Wiley, 2010.

CENTER FOR CHEMICAL PROCESS SAFETY (CCPS). More Incidents That Define Process Safety. New Jersey: Wiley, 2019.

DAGNINO, R. S.; CAPRI JUNIOR, S. Risco ambiental: conceitos e aplicações. Climatologia e Estudos da Paisagem, v. 2, n. 2, p. 50-87, 2007.

FREITAS, K. R; TONETTI, E. L. Usos portuários ou correlatos na área urbana do município de Paranaguá-PR. Revista Nacional de Gerenciamento de Cidades, v. 4, n. 24, p.43-56, 2016. Disponível em: http://dx.doi.org/1 0.17271/2318847242420161323. Acesso em: 15 abr. 2020.

GIDDENS, A. Capitalismo e Moderna Teoria Social. Lisboa: Presença, 2017.

GOUVÊA, P. M; TONETTI. E. L. Avaliação dos riscos de incêndio e explosão na área urbana de Paranaguá-PR. Geografar, v. 12, n. 2, p. 233-250, 2017. Disponível em: http://dx.doi.org/10.5380/geografar.v12i2.52553. Acesso em: 15 abr. 2020.

ILIĆ-KOMATINA, D.; GALJAK, J.; BELOŠEVIĆ, S. Simulation of chemical accidents with acetylene in "Messer Tehnogas" Kraljevo plant by "ALOHA" software program. The University Thought: Publication in Natural Sciences, v. 8, n. 2, p. 19-26, 2018. Disponível em: https://doi.org/10.5937/univtho8-18014. Acesso em: 15 abr. 2020. 
INSTITUTO PARANAENSE DE DESENVOLVIMENTO ECONÔMICO E SOCIAL (IPARDES). Caderno Estatístico do Município de Paranaguá-PR. 2020. Disponível em: http://www.ipardes.gov.br/cadernos/Montapdf. php?Municipio=83200\&btOk=ok. Acesso em: 30 mar. 2020.

LUIZ, R. A. F. Análise da vulnerabilidade aos acidentes tecnológicos no entorno do distrito industrial do município de Paulínia. 95 f. Dissertação (Mestrado em Ciências) - Universidade de São Paulo, São Paulo, 2013.

LYRA, C.; LUCIO, G.; RODRIGUES, L. G. Incêndio provoca explosões em área industrial de Santos, SP. 2015. Disponível em: http://g1.globo.com/sp/santos-regiao/noticia/2015/04/incendio-atinge-industria-no-bairroalemoa-em-santos-litoral-de-sp.html. Acesso em: 06 set. 2020.

MENDES, F. Risco um conceito: do passado que colonizou o presente. Revista Portuguesa de Saúde Pública, v. 20, n. 2. p. 53-62, 2002.

OLIVEIRA, J.; LACERDA, L. C; OLIVEIRA, T. Impactos ambientais ocorridos após o acidente no terminal da Ultracargo. In: VII Encontro Científico do GEPro, 2017, Jaú. Anais... Jaú: Faculdade de Tecnologia de Jahu, 2017. p.164-174.

PARANAGUÁ. Lei Complementar número 62, de 27 agosto de 2007. Institui o zoneamento de uso e ocupação do solo, com objetivo de orientar e ordenar o crescimento da cidade. Disponível em: http://www.paranagua. pr.gov.br/conteudo/transparencia/plano-diretor. Acesso em: 01 jul. 2016.

PORTOS DO PARANÁ. Plano mestre do complexo portuário de Paranaguá e Antonina, 2018. Disponível em: www.portosdoparana.pr.gov.br/sites/portos/arquivos_restritos/files/documento/2019-06/plano_mestre_ dos_portos_de_paranagua_e_antonina.pdf. Acesso em: 25 mar. 2020.

SECRETARIA DE INFRAESTRUTURA E MEIO AMBIENTE (SIMA). Cetesb Multa Ultracargo em R\$ 22,5 milhões pelo incêndio em Santos. 2020. Disponível em: https://www.infraestruturameioambiente.sp.gov.br/2015/04/ cetesb-multa-ultracargo-em-mais-de-22-milhoes-pelo-incendio-no-terminal-da-alemoa/. Acesso em: 15 abr. 2020.

TONETTI, E. L.; NUCCI, J. C.; VALASKI, S. Espacialização de áreas potencialmente poluídas: proximidade de usos incompatíveis no município de Paranaguá-PR. Revista Nacional de Gerenciamento de Cidades, v. 04, n. 25 , p. 33-50, 2016. Disponível em: http://dx.doi.org/10.17271/2318847242520161332. Acesso em: 15 abr. 2020.

TONETTI, E. L.; SCHRÖDER, P. H.; NUCCI, J. C. Risco de explosão: mistura de usos incompatíveis na área urbana de Paranaguá-PR. In: ROSIN, T. A.; ROSIN, T. A. (Orgs.). Riscos e vulnerabilidades ambientais. Tupã: ANAP, 2015. p. 119-137.

TORRISI, D.; PAULA, E. V.; WROBLEWSKY, C. A. Avaliação de ameaças tecnológicas na cidade de Paranaguá/ PR, Brasil. Revista Desenvolvimento e Meio Ambiente, v. 41, p. 174-190, 2017. Disponível em: http://dx.doi. org/10.5380/dma.v41i0.46015. Acesso em: 15 abr. 2020.

WORLD HEALTH ORGANIZATION (WHO). Community emergency preparedness: a manual for managers and policy-makers. Geneva, 1999. 